\title{
Application of NMR Spectroscopy and Conventional Analytical Methods for the Assessment of Wastewater from Food Industry
}

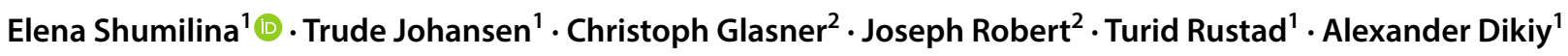

Received: 15 March 2018 / Accepted: 27 September 2018 / Published online: 4 October 2018

(c) The Author(s) 2018

\begin{abstract}
Before wastewater (WW) can be emitted into the municipal treatments plants, its organic matter content has to be assessed and found to comply with legislations. The chemical oxygen demand (COD) and total organic carbon (TOC) are among the most commonly used methods for such analysis. However, volatile organic compounds (VOC) present in the WW might hinder a correct organic matter estimation using these conventional methods. In this study, nuclear magnetic resonance (NMR) was used to identify and quantify VOC in dairy WW. It was determined that the NMR, COD and TOC analyses complement each other providing a more accurate estimation of the organic matter content in WW. In addition, NMR provides data on the metabolic composition of the dairy WW. This information was used to assess the possibility to reutilize dairy WW for the production of high added value compounds.
\end{abstract}

Keywords Dairy wastewaters $\cdot$ NMR $\cdot$ TOC $\cdot$ COD $\cdot$ Added value $\cdot$ Volatile organic compounds

$\begin{array}{ll}\text { Abbreviations } \\ \text { WW } & \text { Wastewater } \\ \text { COD } & \text { Chemical oxygen demand } \\ \text { COD }^{\text {Th }} & \text { Theoretical chemical oxygen demand } \\ \text { TOC } & \text { Total organic carbon } \\ \text { TOC } & \text { Theoretical total organic carbon } \\ \text { DM } & \text { Dry matter content } \\ \text { VOC } & \text { Volatile organic compounds } \\ \text { NMR } & \text { Nuclear magnetic resonance } \\ \text { BOD } & \text { Biochemical oxygen demand } \\ \text { LAB } & \text { Lactic acid bacteria }\end{array}$

\section{Statement of Novelty}

European and international legislations require food industry wastewater (WW) to be precleaned and have a low number of organic compounds before being emitted in the municipal treatment plants. The commonly used methods to determine the organic matter are COD and TOC. These two methods,

Elena Shumilina

elena.shumilina@ntnu.no

1 Norwegian University of Science and Technology (NTNU), Trondheim, Norway

2 Fraunhofer Institute for Environmental, Safety, and Energy Technology UMSICHT, Oberhausen, Germany however, may give skewed results as they do not account for volatile organic compounds (VOC) present in the samples. This research was undertaken to find out whether using NMR as addition to the conventional methods could give more reliable results. It was determined that NMR can be used as a quick and objective analysis to detect VOC in WW. In addition, using NMR it is possible to detect added value compounds present in WW. We suggest using NMR as a tool to assess the potential of WW reuse in food industries and to finetune the development of new bio-refineries.

\section{Introduction}

The agro-food sector faces constant challenges, such as a rising demand for food, feed, fuel, and the limited availability of land and water. In this regard, there is a need to develop new approaches to increase its efficiency and sustainability. Compared to other industrial sectors, the food industry requires large amounts of water. This makes the disposal of the WW challenging for producers and municipal treatment plants $[1,2]$. However, WW from the food industry are easily degradable and less toxic in comparison with other industries [1, 3]. The quality of the WW is under a strict and continuous control as the European Union introduced stringent rules concerning industrial WW emissions [4]. 
The conventional methods used to characterize WW are thoroughly described and frequently updated [5]. Monitoring the aggregate organic constituents is one of the most important requirement of these guidelines. Biochemical oxygen demand (BOD), chemical oxygen demand (COD) and total organic carbon (TOC) are among the most commonly used methods for a general characterization of the WW.

COD is the indirect measurement of the amount of organic matter in a WW sample that can be oxidized by strong inorganic oxidants [5]. The COD value may be used to monitor the efficiency of WW treatment facilities. This involves measuring COD before (influent) and after (effluent) treatment. The EU Directive 91/271/EEC of 21 May 1991 concerning urban WW treatment requires the COD value to be less than $125 \mathrm{mg} / \mathrm{L}$ of $\mathrm{O}_{2}$ for effluent WWs [4]. There are different methods to measure COD [5]. In addition, if the chemical composition of the WW is known it is possible to calculate the theoretical chemical oxygen demand $\left(\mathrm{COD}^{\mathrm{Th}}\right)$. Theoretically, $\mathrm{COD}$ and $\mathrm{COD}^{\mathrm{Th}}$ should be quite similar, since the oxidation of most organic compounds is $95-100 \%$ of the theoretical value [6]. However, the presence of some compounds in the WW can interfere with COD measurements and lead to a greater difference between the $\mathrm{COD}$ and $\mathrm{COD}^{\mathrm{Th}}$ values $[6,7]$. These interfering compounds can be chloride ions, pyridine and related products or VOCs [5].

Both BOD and COD tests are widely used, however they have some drawbacks: $\mathrm{BOD}_{5}$ require 5 days of incubation and the determination of COD produces hazardous wastes. TOC is a possible alternative to both tests because it is faster and potentially more precise than COD $[5,8]$. TOC is defined as the amount of carbon covalently bound to organic compounds present in a sample [9]. TOC is a more suitable and direct assessment of the organic pollutants than BOD or COD, because it directly correlates with the carbon concentration and is not influenced by the presence of some inorganic reducing agents $[5,9]$.

The conventional WW treatment in food industries is mainly aimed at the compliance of the effluent parameters with the legislative requirements and a great amount of WWs from the industries is discarded. However, this approach neglects the potential of WW reuse as a source of high added value compounds. In this regard, the European Commission requires the "redesign of input, waste and side flow strategies to increase resource efficiency and provide added value in food products and processing..." and "use an interdisciplinary research approach for the harmonization of the methods and metrics for an integrated assessment of the sustainability" [10]. The sustainable use of WW would solve the problem of WW disposal and partially cover the disposal and production costs due to the recovery of added value compounds. Food liquid waste is rich in essential nutrients such as metabolites, soluble proteins, lipids and mineral salts that can be recovered and used for food or feed. This makes WW a perspective substrate for bio-refinery [11-16].

Along with conventional methods for the chemical characterization of WW, nuclear magnetic resonance (NMR) spectroscopy can be applied to detect and quantify the organic content in a variety of liquids $[17,18] .{ }^{1} \mathrm{H}$ NMR allows the simultaneous detection and quantification of a wide range of small organic compounds-metabolites. NMR spectroscopy was successfully used to analyze dairy WW composition and the products of lactic acid bacteria (LAB) metabolism such as lactic and acetic acid, ethanol and other bio-refinery relevant compounds $[19,20]$. Such data on the chemical composition of WW may be used to develop biorefinery strategies or to evaluate WW treatment efficiency.

In this article we show how combining conventional and NMR chemical analyses can be used (i) to assess the suitability of using COD and TOC; (ii) to evaluate the efficacy of facility cleaning procedures and (iii) to develop WW utilization strategies.

\section{Materials and Methods}

\section{Sampling}

The WW from a dairy industry was used in this study. The WW collections steps are described below and shown in Fig. 1. Sampling points are shown with dashed arrows (the dairy WW is stored in storage tanks for liquid buffering and $\mathrm{pH}$ neutralization). Storage tank 1 collects the WW from the dairy production process (sample $S T 1$ ). Its content is additionally treated before being drained into the common WW stream. Storage tank 2 contains the WW after filters cleaning

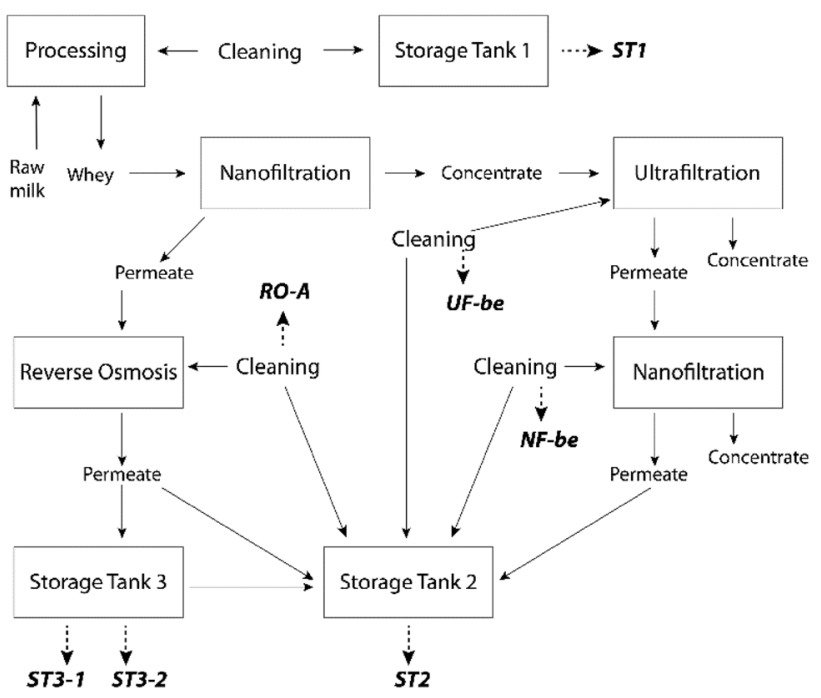

Fig. 1 Flowchart of WW management of the selected dairy. Dashed arrows show the sampling points and sample labeling 
and permeate from the reverse osmosis and nanofiltration (sample ST2). Some part of the reverse osmosis permeate is used separately to pre-clean the processing plant. This WW is stored in storage tank 3 (samples ST3-1 and ST3-2). All the filter systems (reverse osmosis, ultra- and nanofiltration) are cleaned in three sequential steps. During the cleaning process all liquids are in a closed cycle and after are poured into the storage tank 2 . Sampling was carried out instantaneously after the first of the cleaning steps: (i) cleaning of the reverse osmosis system with an acid detergent (sample $R O$ $A$ ); and cleaning of ultra- and nanofiltration systems with base and enzymes (samples UF-be and NF-be).

\section{Methods}

Dry matter content (DM) was determined by drying the samples to a constant weight at $105^{\circ} \mathrm{C}$ for $24 \mathrm{~h}$.

The Lowry method was used to determine the peptide content [21]. The analysis was done in triplicates.

\section{Cuvette Tests}

The chemical oxygen demand (COD) and total organic carbon (TOC) content were measured using the Hach Lange LCK cuvette system (http://www.Hach.com) following the procedures indicated in the different kits.

$C O D$ was measured by oxidizing the WW with a sulphuric acid- potassium dichromate solution in the presence of silver sulphate as a catalyst. Chloride is masked by mercury sulphate. The reduction in the yellow coloration of $\mathrm{Cr}^{6+}$ was evaluated.

TOC was measured by the conversion of total (TC) and inorganic carbons (TIC) to carbon dioxide $\left(\mathrm{CO}_{2}\right)$ by oxidation and acidification respectively. TOC was determined as the difference between the TC and TIC values.

\section{Quantification of Metabolites by NMR}

Sample Preparation for NMR Analysis $540 \mu \mathrm{L}$ of sample were mixed with $60 \mu \mathrm{L}$ of $1 \mathrm{mM}$ of 3-(trimethylsilyl)-propionic-2,2,3,3-d4 acid sodium salt (TSP) in $20 \mathrm{mM}$ phosphate buffer in deuterated water, $\mathrm{pH}$ 7.0, in an Eppendorf tube and centrifuged at 20,000 $\times g$ for $5 \mathrm{~min} .500 \mu \mathrm{L}$ of the centrifuged sample were transferred into a standard $5 \mathrm{~mm}$ NMR tube.

\section{NMR Experiments $1 \mathrm{D}^{1} \mathrm{H}, 2 \mathrm{D}{ }^{1} \mathrm{H}-{ }^{1} \mathrm{H}$ TOCSY, ${ }^{1} \mathrm{H}_{-}{ }^{13} \mathrm{C}$ HSQC} NMR spectra were acquired at $300 \mathrm{~K}$ with a Bruker Avance $600-\mathrm{MHz}$ spectrometer equipped with a 5 -mm z-gradient TXI $(\mathrm{H} / \mathrm{C} / \mathrm{N})$ cryoprobe. All the mentioned above NMR experiments were acquired with the standard Bruker pulse sequences noesygpprld; mlevgpphprzf and hsqcetgpprsisp2.2, correspondingly. Each acquired spectrum was processed with the TopSpin 3.2 (Bruker, Germany) software.
The NMR assignment was performed using registered experiments and the available NMR databases (HMDB and BMRB) $[22,23]$. The spectra were calibrated against an external standard assigning a chemical shift of $0 \mathrm{ppm}$ to the TSP signal both in the ${ }^{1} \mathrm{H}$ and ${ }^{13} \mathrm{C}$ dimensions.

Data Analysis NMR spectra were examined using the TopSpin 3.2 software (Bruker BioSpin). A phase and baseline correction was carried out for all ${ }^{1} \mathrm{H}$ NMR spectra. All signals that were used for the integration have signal-to-noise ratios larger than 10 [24]. The signals for each metabolite were integrated three times and their average values were used to calculate the concentrations.

The theoretical chemical oxygen demand $\left(C O D^{T h}\right)$ is the stoichiometric amount of oxygen required to oxidize a compound to the end products such as $\mathrm{CO}_{2}, \mathrm{NH}_{3}, \mathrm{H}_{2} \mathrm{PO}_{4}^{-}$, $\mathrm{SO}_{4}{ }^{2-}$, and $\mathrm{H}_{2} \mathrm{O}$ [7]:

$$
\begin{gathered}
\mathrm{C}_{n} \mathrm{H}_{m} \mathrm{O}_{e} \mathrm{X}_{k} \mathrm{~N}_{j} \mathrm{~S}_{i} \mathrm{P}_{h}+b \mathrm{O}_{2} \rightarrow n \mathrm{CO}_{2}+\frac{m-k-3 j-2 i-3 h}{2} \\
\mathrm{H}_{2} \mathrm{O}+k \mathrm{HX}+j \mathrm{NH}_{3}+i \mathrm{H}_{2} \mathrm{SO}_{4}+h \mathrm{H}_{3} \mathrm{PO}_{4}
\end{gathered}
$$

$b=n+\frac{m-k-3 j-2 i-3 h}{4}-\frac{e}{2}+2 i+2 h$

The resulting $\mathrm{COD}^{\mathrm{Th}}$ of all metabolites found in analyzed WW was determined from Eq. 1:

$C O D^{T h}=32 * b * C$

where 32 is the weight of one molecule of oxygen, $b$ is the number of oxygen molecules used for compound oxidation and $C$ is the molar concentration of the compound in WW.

The theoretical total organic carbon $\left(T O C^{T h}\right)$ of a compound $\mathrm{CxHyOz}$ can be calculated using Eq. 2:

$T O C^{T h}=12 * x * C$

where 12 is the carbon weight, $x$ is the number of carbon atoms in one molecule of the compound and $C$ is the molar concentration of the compound in WW.

\section{Results}

\section{Influence of Volatile Organic Compounds on the Experimental Measurement of COD and TOC of WW}

Previous research has shown that VOC may interfere with the measurement of COD and TOC and lead to an underestimation of COD [5]. For instance, in the presence of acetic acid, the error in COD detection can be up to 50\% [25]. Therefore, the possible influence of VOC on TOC and COD results was estimated by calculating the relative amount of 
VOC to the total amount of organic compounds found in WW, including peptides, non- and volatile metabolites. All metabolites detected by NMR that have a boiling point less than or equal to $250{ }^{\circ} \mathrm{C}$ measured at a standard pressure of $101.3 \mathrm{kPa}$ were classified as VOC (Art.2; paragraph 5) [26]. The results are shown in Table 1.

The high amount of VOC can explain the results of conventional analyses of WW from storage tanks 2 and 3 (Table 2). The detected by NMR and Lowry method amount of metabolites and peptides exceeds the detected dry matter of ST2, ST3-1 and ST3-2 (more than 100\%, Table 1). The relative content of VOC to DM in these samples is 53, 62 and 79\%, respectively. The volatilization of such significant amount of VOC during the DM analysis may skew the results. On the other hand, the exclusion of VOC from the calculation results allows estimate the amount of detected non-volatile organic compounds $(72,63$ and 43\%, respectively, Table 1).
The possible influence of VOC on COD and TOC may be estimated by calculating the ratios of their $\mathrm{COD}^{\mathrm{Th}}$ and TOC $^{\text {Th }}$ to experimentally measured parameters $\left(\mathrm{COD}^{\mathrm{Th}}{ }_{\text {vOC }}{ }^{\prime}\right.$ COD and TOC $^{\text {Th }}$ voC $/$ TOC). Both theoretical values were calculated using the concentrations of metabolites that were found by NMR using Eqs. 1 and 2, respectively (Tables 3, 4). The maximal $\mathrm{COD}^{\mathrm{Th}}{ }_{\text {VOC }}$ and TOC ${ }^{\mathrm{Th}}$ vOC values were found in the cleaning water from ultra- and nanofiltration plants (UF-be and NF-be). However, their relative content of VOC to $\mathrm{DM}$ is less than $20 \%$. Therefore, the COD/TOC detection for $U F$-be and NF-be will be less skewed than for the ST2, ST3-1 and ST3-2 samples. In the case of storage tank 3 the $\mathrm{COD}^{\mathrm{Th}}{ }_{\text {VOC }} / \mathrm{COD}$ and $\mathrm{TOC}^{\mathrm{Th}}{ }_{\text {VoC }} / \mathrm{TOC}$ ratios exceed $50 \%$ (Tables 3, 4).

Besides WW from storage tanks 2 and 3, the relative content of VOC to all detected organic compounds is high in sample $R O$ - $A$. However, these compounds will not interfere with the COD and TOC measurements, since all the detected
Table 1 Relative amount of metabolites to dry matter in percentage $(\%)$
Table 2 Results of the conventional analyses using a Hach LCK cuvette system

\begin{tabular}{|c|c|c|c|c|c|c|c|}
\hline & $S T 1$ & $S T 2$ & ST3-1 & ST3-2 & $R O-A$ & $U F-b e$ & $N F-b e$ \\
\hline Lactate & 2.79 & 55.44 & 57.32 & 40.37 & 0.05 & 6.15 & 3.34 \\
\hline Lactose & 33.64 & 11.02 & - & 2.79 & - & 53.63 & 15.68 \\
\hline Citrate & 1.70 & - & - & - & - & 0.91 & - \\
\hline Alanine & 0.02 & 0.18 & - & - & - & 0.02 & 0.21 \\
\hline$C^{V O C} / C^{(V O C+p e p t i d e s+n o n-V O C)}, \%$ & 3.5 & 42.3 & 49.8 & 64.7 & 68.7 & 8.7 & 28.0 \\
\hline$C^{V O C} / \mathrm{DM}, \%$ & 2.6 & 52.9 & 62.2 & 79.0 & 0.1 & 6.8 & 15.1 \\
\hline$C^{(V O C+p e p t i d e s+n o n-V O C)} / \mathrm{DM}, \%$ & 74.1 & 125.2 & 125.0 & 122.2 & 0.2 & 78.2 & 54.0 \\
\hline$C^{(\text {peptides+non-VOC) }} / \mathrm{DM}, \%$ & 71.5 & 72.3 & 62.8 & 43.2 & 0 & 71.4 & 38.8 \\
\hline
\end{tabular}

$C$ concentration $(\mathrm{mg} / \mathrm{L})$, non-VOC non-volatile organic compounds, $V O C$ volatile organic compounds, $D M$ dry matter $(\mathrm{mg} / \mathrm{L})$

\begin{tabular}{|c|c|c|c|c|c|c|c|}
\hline Samples & $S T 1$ & $S T 2$ & ST3-1 & ST3-2 & $R O-A$ & $U F-b e$ & $N F-b e$ \\
\hline \multicolumn{8}{|l|}{$\mathrm{pH}$} \\
\hline- & 11.4 & 4.4 & 4.5 & 4.4 & 1.7 & 7.8 & 10.4 \\
\hline St. dev., \% & 0.9 & 2.3 & 2.2 & 2.3 & 5.9 & 1.3 & 1.0 \\
\hline \multicolumn{8}{|l|}{ TOC } \\
\hline $\mathrm{mg} / \mathrm{L}$ & 1074 & 883 & 497 & 615 & 21.6 & 4886 & 2727 \\
\hline St. dev., \% & 5.9 & 4.8 & 8.5 & 3.6 & 69.4 & 2.7 & 2.9 \\
\hline \multicolumn{8}{|l|}{ COD } \\
\hline $\mathrm{mg} / \mathrm{L} \mathrm{O}_{2}$ & 3318 & 2304 & 1556 & 1546 & b.1 & 12,297 & 7218 \\
\hline St. dev., \% & 1.4 & 0.7 & 2.2 & 0.5 & - & 0.0 & 1.0 \\
\hline \multicolumn{8}{|l|}{ Dry matter } \\
\hline $\mathrm{mg} / \mathrm{L}$ & 2125 & 1156 & 1050 & 900 & 2958 & 10,233 & 5258 \\
\hline St. dev., \% & 0.1 & 0.5 & 0.2 & 1.2 & 0.1 & 0.0 & 0.0 \\
\hline \multicolumn{8}{|l|}{ Peptides } \\
\hline $\mathrm{mg} / \mathrm{L}$ & 707.9 & 65.2 & 57.3 & - & - & 1093.1 & 1031.1 \\
\hline
\end{tabular}

Peptides were quantified using Lowry test b.l. below limits of detection 
Table $3 \mathrm{COD}^{\mathrm{Th}}$ of wastewater calculated from NMR measurements $(\mathrm{mg} / \mathrm{L})$
Table $4 \mathrm{TOC}^{\mathrm{Th}}$ of wastewater calculated from NMR measurements $(\mathrm{mg} / \mathrm{L})$

\begin{tabular}{llllllll}
\hline & $S T 1$ & $S T 2$ & $S T 3-1$ & $S T 3-2$ & $R O-A$ & UF-be & NF-be \\
\hline Acetate & 29.90 & 414.01 & 471.58 & 453.73 & 0.48 & 51.88 & 10.08 \\
Butyrate & 14.62 & 24.62 & 40.30 & 2.44 & - & - & - \\
Propionate & 6.98 & 2.42 & 4.29 & 2.65 & - & - & - \\
Formate & 0.84 & 6.19 & 5.54 & 8.40 & - & 1.27 & 0.80 \\
Succinate & 1.99 & 6.76 & - & 4.43 & - & 4.37 & 4.86 \\
Benzoate & - & 4.62 & 6.60 & 4.81 & - & 8.09 & 11.52 \\
Ethanol & 9.22 & 146.49 & 156.72 & 413.54 & 3.92 & 45.06 & 9.52 \\
Methanol & 0.25 & 0.42 & 0.44 & 0.50 & 1.13 & 0.19 & 0.21 \\
Acetone & - & 20.97 & 10.92 & 24.45 & - & 5.09 & 1.41 \\
Propylene glycol & 9.11 & 109.52 & 109.29 & 4.39 & - & 1006.75 & 1287.44 \\
Acetoin & - & 50.50 & 30.43 & 55.63 & - & 11.78 & 2.94 \\
Lactate & 63.13 & 682.56 & 641.24 & 387.16 & 1.50 & 670.64 & 186.96 \\
Lactose & 802.02 & 142.85 & - & 28.19 & - & 6156.75 & 925.06 \\
Citrate & 27.09 & - & - & - & - & 69.95 & - \\
Alanine & 0.52 & 2.23 & - & - & - & 1.75 & 12.05 \\
COD $^{\text {Th }}$ & 966 & 1614 & 1477 & 1390 & 7 & 8034 & 2453 \\
COD $^{\text {Th }}$ voc & 73 & 787 & 836 & 975 & 6 & 1134 & 1329 \\
COD $^{\text {Th }}$ voC $/$ COD $\%$ & 2.2 & 34.1 & 53.7 & 63.1 & - & 9.2 & 18.4 \\
\hline
\end{tabular}

$V O C$ volatile organic compounds

\begin{tabular}{|c|c|c|c|c|c|c|c|}
\hline & $S T 1$ & $S T 2$ & ST3-1 & ST3-2 & $R O-A$ & $U F-b e$ & $N F-b e$ \\
\hline Acetate & 11.21 & 155.25 & 176.84 & 170.15 & 0.18 & 19.46 & 3.78 \\
\hline Butyrate & 4.39 & 7.39 & 12.09 & 0.73 & - & - & - \\
\hline Propionate & 2.24 & 0.78 & 1.38 & 0.85 & - & - & - \\
\hline Formate & 0.63 & 4.65 & 4.15 & 6.30 & - & 0.95 & 0.60 \\
\hline Succinate & 0.85 & 2.90 & - & 1.90 & - & 1.87 & 2.08 \\
\hline Benzoate & - & 1.62 & 2.31 & 1.68 & - & 2.83 & 4.03 \\
\hline Ethanol & 2.30 & 36.62 & 39.18 & 103.39 & 0.98 & 11.27 & 2.38 \\
\hline Methanol & 0.06 & 0.10 & 0.11 & 0.12 & 0.28 & 0.05 & 0.05 \\
\hline Acetone & - & 5.90 & 3.07 & 6.88 & - & 1.43 & 0.40 \\
\hline Propylene glycol & 2.56 & 30.80 & 30.74 & 1.23 & - & 283.15 & 362.09 \\
\hline Acetoin & - & 18.94 & 11.41 & 20.86 & - & 4.42 & 1.10 \\
\hline Lactate & 23.67 & 255.96 & 240.46 & 145.19 & 0.56 & 251.49 & 70.11 \\
\hline Lactose & 300.76 & 53.57 & - & 10.57 & - & 2308.78 & 346.90 \\
\hline Citrate & 13.54 & - & - & - & - & 34.97 & - \\
\hline Alanine & 0.19 & 0.84 & - & - & - & 0.66 & 4.52 \\
\hline $\mathrm{TOC}^{\mathrm{Th}}$ & 362.4 & 575.3 & 521.7 & 469.9 & 2.0 & 2921.3 & 798.0 \\
\hline TOC $^{\text {Th }}{ }_{\text {VOC }}$ & 24.3 & 264.9 & 281.3 & 314.1 & 1.4 & 325.4 & 376.5 \\
\hline TOC $^{\mathrm{Th}}{ }_{\text {voc }} / \mathrm{TOC}, \%$ & 2.3 & 30.0 & 56.6 & 51.1 & 6.7 & 6.7 & 13.8 \\
\hline
\end{tabular}

VOC volatile organic compounds

organic compounds in this sample compose only $0.2 \%$ of its DM.

In this example study, NMR allowed to identify the WW samples with the highest relative content of VOC. However, the WW analysis requires the use of both conventional methods and NMR spectroscopy. If only conventional methods are used, VOC are not detected which might lead to an underestimation of the COD/TOC. If, on the other hand, only NMR is utilized, the impact of VOC on the TOC and COD measurement might be overemphasized. 


\section{Cleaning Efficacy Analysis}

The dairy filtration systems are subject to a periodical three-step sequential cleaning. The WW obtained from the first step of the reverse osmosis, ultra- and nanofiltration plant cleaning was analyzed, since it contained the highest number of metabolites. The reverse osmosis filter was cleaned with acid (sample $R O-A$ ) while the ultraand nano-filtration systems were cleaned with base and enzymes (samples $U F-b e$ and NF-be). The NMR spectra of all studied samples are shown in Fig. 2.

\section{Cleaning of Reverse Osmosis Filter with Acid Detergent}

The reverse osmosis cleaning water is divided into two parts. The first part is used to pre-clean the production plants and is collected in storage tank 3 . The remaining liquid is drained into storage tank 2 (Fig. 1). The first step of reverse osmosis plant cleaning degrades most of the organic compounds with acidic detergent. The COD of $R O-A$ was below the detection limit and its TOC was also low $(22 \mathrm{mg} / \mathrm{L})$. Only a few compounds out of the $3 \mathrm{~g} / \mathrm{L}$ of $R O$-A dry matter can be identified by NMR and conventional methods: ethanol, methanol, acetate and lactate, for total of $0.05 \%$ from the sample DM (Fig. 2; Table 1). Since the main detected metabolites are VOC, and COD value cannot be detected, the TOC measurement is also at risk of being underestimated. Nevertheless, the $\mathrm{TOC}^{\mathrm{Th}}{ }_{\mathrm{VOC}}{ }^{\prime}$ TOC value of $R O-A$ is relatively low (6.7\%) indicating that already the first step of cleaning produces $\mathrm{WW}$ with acceptable COD and TOC values (COD $<125 \mathrm{mg} / \mathrm{L}$ [4]).

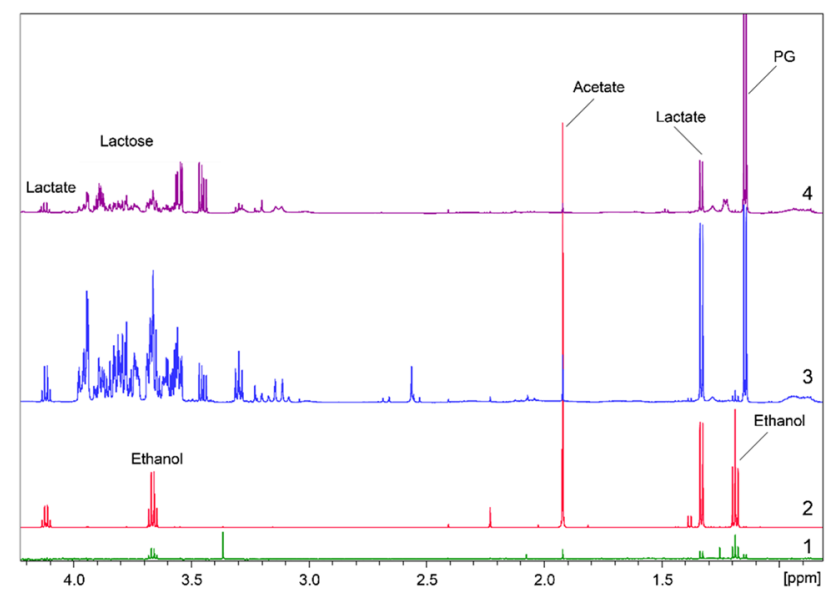

Fig. 2 Part of the 1D $600 \mathrm{MHz}{ }^{1} \mathrm{H}$ NMR spectra of WW samples from the first step of filter cleaning : 1 (green, zoomed 40 times)-RO-A; 2 (red)-RO; 3 (blue)-UF-be; 4 (purple)-NF-be. (Color figure online)
Cleaning the Ultra- and Nano-filtration Plants with Base and Enzymes

Cleaning the dairy nano- and ultrafiltration systems with base and enzymes produces WW similar in composition. Both WW samples have similar content of peptides and a metabolic profile rich in lactose with neutral or basic $\mathrm{pH}$. Their VOC content is relatively low and the high COD and TOC values of both samples show that the WW processed in this way cannot be poured directly into the municipal sewage system. Additional cleaning steps are therefore necessary for these two filtration systems. However, the metabolic composition of both samples makes them a suitable supplement for the production of lactic acid. The transferability to other dairies needs should be evaluated individually, because the WW composition can vary significantly depending on the products and the used processing technologies and applied cleaning steps.

\section{Bio-refinery Potential: Lactic Acid Production}

To identify the biochemical process that takes place in WW treatment facilities, the kinetics and bacterial composition needs to be studied. However, an NMR analysis allows to determine the metabolite composition of WW and therefore to speculate on the possible bio-chemical processes. In this example, the combination of NMR results and data from the conventional methods allows to suggest using dairy WW for the production of lactic acid via fermentation.

The metabolites accounting for a significant part of the DM of the WW samples from storage tanks and filters were found to be lactate and lactose (more than $30 \%$, Table 1). The latter is a carbohydrate that converts to lactate (LA) upon fermentation by LAB.

The production of LA in bio-refinery plants is an important market. The global LA market was estimated to be 1 220,000 tons in 2016 and is expected to increase by $17 \%$ from 2017 to 2021 [27, 28]. LA can be synthesized industrially through chemical synthesis or by microbial or fungal fermentations [29-33]. LA is produced by fermenting different carbohydrates by a variety of Lactobacilli strains. The use of carbohydrate sources depends on their price, availability, and on the cost of LA recovery and purification. LA fermentation occurs over a period of $1-2$ days at $40-60{ }^{\circ} \mathrm{C}$ with a $\mathrm{pH}$ of 5-7 [29]. LA yield ranges between 90 and 95\% from carbohydrate sources and depends on the $\mathrm{pH}$ and temperature. For instance the fermentation of cheese whey with different LAB and yeast gives 9-96 g/L of LA [30, 34].

In the studied WW, the highest concentration of lactose was found in the samples UF-be and NF-be $(5.5$ and $0.8 \mathrm{~g} / \mathrm{L}$, respectively, Table 5). Therefore, 5.7 and $0.9 \mathrm{~g} / \mathrm{L}$ of LA can be obtained out of ultra- and nano-filtration cleaning water, respectively. Lower quantities of lactose were also found in 
Table 5 Concentration $(C)$ of water-soluble metabolites, $\mathrm{mg} / \mathrm{L}$

\begin{tabular}{|c|c|c|c|c|c|c|c|c|c|c|c|c|c|c|}
\hline & \multicolumn{2}{|l|}{$S T 1$} & \multicolumn{2}{|l|}{$S T 2$} & \multicolumn{2}{|l|}{ ST3-1 } & \multicolumn{2}{|l|}{ ST3-2 } & \multicolumn{2}{|c|}{$R O-A$} & \multicolumn{2}{|l|}{$U F$-be } & \multicolumn{2}{|l|}{$N F-b e$} \\
\hline & $\mathrm{C}$ & $\%$ & $\mathrm{C}$ & $\%$ & $\mathrm{C}$ & $\%$ & $\mathrm{C}$ & $\%$ & $\mathrm{C}$ & $\%$ & $\mathrm{C}$ & $\%$ & $\mathrm{C}$ & $\%$ \\
\hline \multicolumn{15}{|l|}{ VOC } \\
\hline Acetate & 28.1 & 0.3 & 388.8 & 0.2 & 442.8 & 0.5 & 426.1 & 1.1 & 0.4 & 6.6 & 48.7 & 0.6 & 9.5 & 1.6 \\
\hline Butyrate & 8.1 & 4.2 & 13.6 & 2.0 & 22.2 & 1.7 & 1.3 & 8.5 & - & - & - & - & - & - \\
\hline Propionate & 4.6 & 2.1 & 1.6 & 7.1 & 2.8 & 1.2 & 1.8 & 1.0 & - & - & - & - & - & - \\
\hline Formate & 2.4 & 9.4 & 17.8 & 1.6 & 15.9 & 5.6 & 24.2 & 1.1 & - & - & 3.6 & 3.4 & 2.3 & 6.5 \\
\hline Succinate & 2.1 & 3.1 & 7.1 & 4.2 & - & - & 4.7 & & - & - & 4.6 & 2.6 & 5.1 & 1.4 \\
\hline Benzoate & - & - & 2.4 & 8.1 & 3.4 & 9.1 & 2.4 & 3.4 & - & - & 4.1 & 0.6 & 5.9 & 4.4 \\
\hline Ethanol & 4.4 & 20.5 & 70.3 & 2.2 & 75.3 & 1.5 & 198.6 & 1.4 & 1.9 & 4.6 & 21.6 & 6.8 & 4.6 & 20.4 \\
\hline Methanol & 0.2 & 2.7 & 0.3 & 2.7 & 0.3 & 15.0 & 0.3 & 1.1 & 0.8 & 0.4 & 0.1 & 2.7 & 0.1 & 10.7 \\
\hline Acetone & - & - & 9.5 & 2.2 & 5.0 & 13.3 & 11.1 & 2.2 & - & - & 2.3 & 4.8 & 0.6 & 14.9 \\
\hline Propylene glycol & 5.4 & 3.3 & 65.1 & 1.0 & 65.0 & 0.1 & 2.6 & 2.3 & - & - & 598.5 & 0.1 & 765.4 & 0.2 \\
\hline Acetoin & - & - & 34.8 & 0.1 & 20.9 & 1.2 & 38.3 & 0.8 & - & - & 8.1 & 6.6 & 2.0 & 18.1 \\
\hline \multicolumn{15}{|l|}{ Non-VOC } \\
\hline Lactate & 59.2 & 0.5 & 640.6 & 0.5 & 601.8 & 0.4 & 363.4 & 0.2 & 1.4 & 1.3 & 629.4 & 0.8 & 175.5 & 3.2 \\
\hline Lactose & 714.9 & 1.0 & 127.3 & 6.9 & - & - & 25.1 & 19.4 & - & - & 5488.2 & 1.2 & 824.6 & 0.2 \\
\hline Citrate & 36.1 & 3.3 & - & - & - & - & - & - & - & - & 93.3 & 1.0 & - & - \\
\hline Alanine & 0.5 & 5.1 & 2.1 & 26.5 & - & - & - & - & - & - & 1.6 & 16.9 & 11.2 & 6.9 \\
\hline
\end{tabular}

$\%$ standard deviation in percentage

VOC volatile organic compounds

ST1, ST2 and ST3. In addition, UF-be, NF-be, ST3 and ST2 were found to contain a significant amount of LA $(0.6,0.2$, $\sim 0.5$ and $0.6 \mathrm{~g} / \mathrm{L}$, respectively). Therefore, the possible LA yield only from $U F-b e$ can rise to $6.4 \mathrm{~g} / \mathrm{L}$. The optimization of WW cycling within the studied dairy may help to avoid the dilution of lactose-rich fractions and increase the final concentration of LA to be comparable with the $9-96 \mathrm{~g} / \mathrm{L}$ of LA output from specialized bio-refineries [30].

LA production by LAB requires to control the $\mathrm{pH}$ in the fermented liquid, as otherwise the LA yield might be reduced by a twofold [35]. The WW with the highest lactose yield $U F$-be, $N F$-be and $S T 1$ have a basic $\mathrm{pH}(7.8,10.4$ and 11.4 , respectively). Although the $S T 2$ and $S T 3$ samples did not contain a significant amount of lactose, the addition of these WW with low pH will neutralize the basic WW and will make them more suitable for fermentation.

The data obtained during this investigation can be used as a starting point to optimize the use of WW and potentially develop a LA bio-refinery (Fig. 3). Storage tank 2 can be used for LAB fermentation. Its relatively low $\mathrm{pH}$ can be neutralized by the periodic addition of lactose rich WW after the ultra- and nanofiltration plant cleaning. The WW from storage tank 1 can additionally increase the $\mathrm{pH}$ and supply lactose into the bio-refinery. The ratio of each $\mathrm{WW}$ in the final bio-refinery has to be further studied together with the variability of WW at different time points. However, NMR analysis allows to detect and quantify carbon sources and the final products of LAB fermentation in one measurement

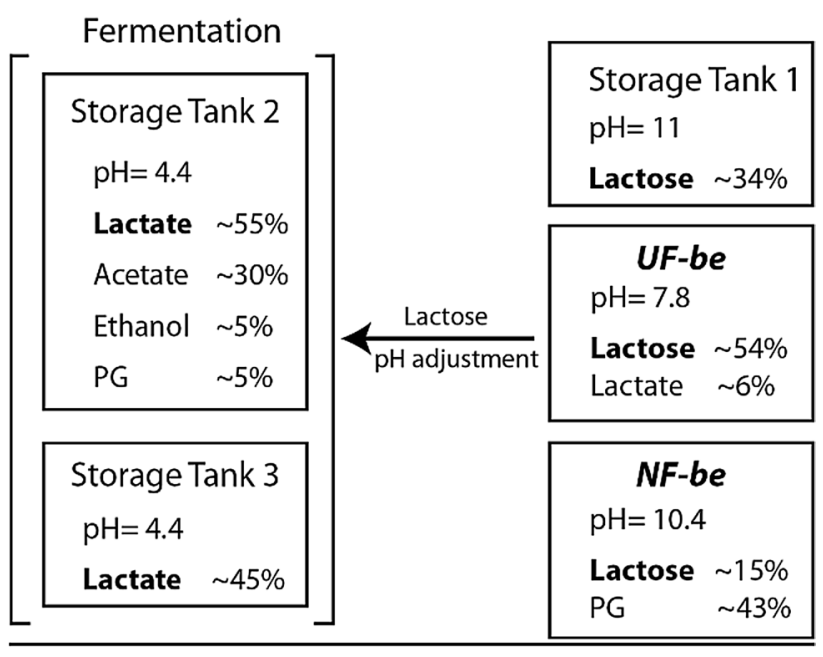

Fig. 3 Proposed cycle of WW in a LA bio-refinery. The amount of lactose and lactic acid is shown as a percentage from DM. The amount of acetate, ethanol and PG (propylene glycol) relative to the total metabolite amount detected by NMR is also shown

that can be done in less than in 10 min without any sample modifications.

Besides LA and lactose, the studied WW samples contain other valuable products, such as acetic and other organic acids, ethanol and propylene glycol (Table 5). These compounds can be used in a wide range of applications [36]. Their concentration in the WW cannot be compared with the 
Table 6 Relative amount of each metabolite to total amount of all metabolites found by $\operatorname{NMR}(\%)$

\begin{tabular}{lrrrrrrr}
\hline & $S T 1$ & \multicolumn{1}{c}{$S T 2$} & \multicolumn{1}{c}{$S T 3-1$} & \multicolumn{1}{c}{$S T 3-2$} & $R O-A$ & $U F-b e$ & NF-be \\
\hline Acetate & 3.2 & 28.1 & 35.3 & 38.7 & 10.0 & 0.7 & 0.5 \\
Butyrate & 0.9 & 1.0 & 1.8 & 0.1 & 0.0 & 0.0 & 0.0 \\
Propionate & 0.5 & 0.1 & 0.2 & 0.2 & 0.0 & 0.0 & 0.0 \\
Formate & 0.3 & 1.3 & 1.3 & 2.2 & 0.0 & 0.1 & 0.1 \\
Succinate & 0.2 & 0.5 & 0.0 & 0.4 & 0.0 & 0.1 & 0.0 \\
Benzoate & 0.0 & 0.2 & 0.3 & 0.2 & 0.0 & 0.1 & 0.3 \\
Ethanol & 0.5 & 5.1 & 6.0 & 18.1 & 41.9 & 0.3 & 0.3 \\
Methanol & 0.0 & 0.0 & 0.0 & 0.0 & 16.8 & 0.0 & 0.0 \\
Acetone & 0.0 & 0.7 & 0.4 & 1.0 & 0.0 & 0.0 & 0.0 \\
Propylene glycol & 0.6 & 4.7 & 5.2 & 0.2 & 0.0 & 8.7 & 42.5 \\
Acetoin & 0.0 & 2.5 & 1.7 & 3.5 & 0.0 & 0.1 & 0.1 \\
Lactate & 6.8 & 46.4 & 47.9 & 33.0 & 31.3 & 9.1 & 9.7 \\
Lactose & 82.6 & 9.2 & 0.0 & 2.3 & 0.0 & 79.5 & 45.8 \\
Citrate & 4.2 & 0.0 & 0.0 & 0.0 & 0.0 & 1.4 & 0.0 \\
Alanine & 0.1 & 0.2 & 0.0 & 0.0 & 0.0 & 0.0 & 0.6 \\
\hline
\end{tabular}

amount of dry matter in the samples, as all these compounds are VOC. Therefore, the amount of each volatile compound relative to the amount of all metabolites found by NMR was calculated and reported in Table 6. Acetic acid composes about $30 \%$ of all metabolites detected by NMR in storage tank 2 and 3 (Table 6). The amount of ethanol varies in the tanks from 5 to $18 \%$. A large part of NF-be is composed of propylene glycol (43\%). Therefore, the current investigation indicates that dairy WW are composed of a variety of value added compounds that could be utilized, instead of expensively processed and discarded with the water as it is currently done.

\section{Conclusions}

In this study a chemical analysis of dairy WWs was carried out by $1 \mathrm{D}{ }^{1} \mathrm{H}$ NMR spectroscopy and using the Hach Lange LCK cuvette system. The metabolite and dry matter content, TOC and COD values of WW from different process steps were determined and compared. Lactose, lactic acid and VOC were detected and quantified by NMR. The estimation of VOC impact on COD and TOC measurement requires the joint use of conventional and NMR analyses. Such approach can be used to identify WW where the COD and TOC values are potentially underestimated. The proposed NMR assessment can be a useful additional control of WW quality before it is discarded.

In addition, the WW from different dairy production steps were found to be rich in lactate and lactose and other high added value compounds. It was therefore proposed to use the NMR analysis for optimization of dairy WW recycling. This investigation indicates that NMR spectroscopy is a powerful addition to conventional methods that allows a more comprehensive characterization of WWs from the food industry.

Acknowledgements This work was done as a part of the project: BioSuck-decision support system on optimized waste collection by vacuum technology with simultaneous production of bioenergy from wastes. The activity was conducted under SUSFOOD, an FP7 ERA-Net on Sustainable Food Production and Consumption. We thank RCN (the Norwegian Project Number is 239423/E40) and the German Federal Ministry of Education and Research (Project Number 031A433A) for the financial support.

Open Access This article is distributed under the terms of the Creative Commons Attribution 4.0 International License (http://creativeco mmons.org/licenses/by/4.0/), which permits unrestricted use, distribution, and reproduction in any medium, provided you give appropriate credit to the original author(s) and the source, provide a link to the Creative Commons license, and indicate if changes were made.

\section{References}

1. Mavrov, V., Bélières, E.: Reduction of water consumption and wastewater quantities in the food industry by water recycling using membrane processes. Desalination 131(1), 75-86 (2000)

2. Cicek, N.: A review of membrane bioreactors and their potential application in the treatment of agricultural wastewater. Can. Biosyst. Eng. 45, 6.37-6.37 (2003)

3. Abdallh, M.N., Abdelhalim, W.S., Abdelhalim, H.S.: Industrial wastewater treatment of food industry using best techniques. Int. J. Eng. Sci. Invent. 5(8), 15-28 (2016)

4. Council Directive 91/271/EEC of 21 May 1991 concerning urban waste-water treatment. Council of the European Union (1991)

5. Rice, E.W., et al.: Standard Methods for the Examination of Water and Wastewater. American Public Health Association, American Water Works Association, Water Environment Federation, Virginia (2012)

6. Clesceri, L.S., Greenberg, A.E., Eaton, A.D.: Chemical Oxygen Demand (COD), in Standard Methods for the Examination of 
Water and Wastewater, 20th edn. APHA American Public Health Association, Washington, DC (1998)

7. Baker, J.R., Milke, M.W., Mihelcic, J.R.: Relationship between chemical and theoretical oxygen demand for specific classes of organic chemicals. Water Res. 33(2), 327-334 (1999)

8. Dubber, D., Gray, N.F.: Replacement of chemical oxygen demand (COD) with total organic carbon (TOC) for monitoring wastewater treatment performance to minimize disposal of toxic analytical waste. J. Environ. Sci. Health A 45(12), 1595-1600 (2010)

9. Maestre, S., et al.: A system for the direct determination of the nonvolatile organic carbon, dissolved organic carbon, and inorganic carbon in water samples through inductively coupled plasma atomic emission spectrometry. Anal. Chem. 75(1), 111-117 (2003)

10. SFS-19-2016-2017: ERA-NET Cofund: public-public partnerships in the bioeconomy. 2016, CORDIS, EU Publication Office

11. Lim, S.-J., et al.: Volatile fatty acids production from food wastes and its application to biological nutrient removal. Bioprocess Biosyst. Eng. 22(6), 543-545 (2000)

12. Bozell, J.J., Petersen, G.R.: Technology development for the production of biobased products from biorefinery carbohydrates- the US Department of Energy's “Top 10" revisited. Green Chem. 12(4), 539-554 (2010)

13. Eilersen, A.M., Henze, M., Kløft, L.: Effect of volatile fatty acids and trimethylamine on denitrification in activated sludge. Water Res. 29(5), 1259-1266 (1995)

14. Lee, W.S., et al.: A review of the production and applications of waste-derived volatile fatty acids. Chem. Eng. J. 235(Supplement C), 83-99 (2014)

15. Panesar, P.S., Kaur, S.: Bioutilisation of agro-industrial waste for lactic acid production. Int. J. Food Sci. Technol 50(10), 2143$2151(2015)$

16. Kapdan, I.K., Kargi, F.: Bio-hydrogen production from waste materials. Enzyme Microbial. Technol. 38(5), 569-582 (2006)

17. Fan, T.W.-M., Lane, A.N.: Structure-based profiling of metabolites and isotopomers by NMR. Prog. Nucl. Magn. Reson. Spectrosc. 52(2), 69-117 (2008)

18. Beckonert, O., et al.: Metabolic profiling, metabolomic and metabonomic procedures for NMR spectroscopy of urine, plasma, serum and tissue extracts. Nat. Protoc. 2(11), 2692-2703 (2007)

19. Juodeikiene, G., et al.: Evaluation of the potential of utilizing lactic acid bacteria and dairy wastewaters for methane production. Energy Explor. Exploit. 35, 388-402 (2017)

20. Juodeikiene, G., et al.: Potential of an exploitation of acid-tolerant antimicrobial microorganisms evolving enzyme systems for the utilization of dairy by-products and lignocellulosic biomass to lactic acid. Front. Bioeng. Biotechnol. 4(92), 1-4 (2016)

21. Classics Lowry, O., et al.: Protein measurement with the Folin phenol reagent. J. Biol. Chem. 193, 265-275 (1951)
22. Wishart, D.S., et al.: HMDB: the human metabolome database. Nucl. Acids Res. 35(suppl_1), D521-D526 (2007)

23. Ulrich, E.L., et al.: BioMagResBank. Nucl. Acids Res. 36(suppl_1), D402-D408 (2007)

24. Maniara, G., et al.: Method performance and validation for quantitative analysis by $1 \mathrm{H}$ and 31P NMR spectroscopy. Applications to analytical standards and agricultural chemicals. Anal. Chem. 70(23), 4921-4928 (1998)

25. Farina, R., et al.: Misassumptions in cod measurement in wastewaters containing high concentration of VFA. In: 10th IWA Conference on Anaerobic Digestion. Montreal, Canada (2004)

26. Parlament, E., Union, C.o.tE.: Directive 2004/42/CE of the European Parliament and of the Council of 21 April 2004 on the limitation of emissions of volatile organic compounds due to the use of organic solvents in certain paints and varnishes and vehicle refinishing products and amending Directive 1999/13/EC, in 2004/42/ CE. E. Parlament and C.o.t.E. Union (2004)

27. TechNavio, G.: Lactic Acid Market 2017-2021. TechNavio, London (2017)

28. Abdel-Rahman, M.A., Tashiro, Y., Sonomoto, K.: Lactic acid production from lignocellulose-derived sugars using lactic acid bacteria: overview and limits. J. Biotechnol. 156(4), 286-301 (2011)

29. Ghaffar, T., et al.: Recent trends in lactic acid biotechnology: a brief review on production to purification. J. Radiat. Res. Appl. Sci. 7(2), 222-229 (2014)

30. Abdel-Rahman, M.A., Tashiro, Y., Sonomoto, K.: Recent advances in lactic acid production by microbial fermentation processes. Biotechnol. Adv. 31(6), 877-902 (2013)

31. Ding, S., Tan, T.: L-lactic acid production by Lactobacillus casei fermentation using different fed-batch feeding strategies. Process Biochem. 41(6), 1451-1454 (2006)

32. Teusink, B., Smid, E.J.: Modelling strategies for the industrial exploitation of lactic acid bacteria. Nat. Rev. Microbiol 4(1), 46-56 (2006)

33. Ramanjooloo, A., et al.: 1H NMR quantitative assessment of lactic acid produced by biofermentation of cane sugar juice. Spectrosc. Lett. 42(6-7), 296-304 (2009)

34. Plessas, S., et al.: Lactic acid production by mixed cultures of Kluyveromyces marxianus, Lactobacillus delbrueckii ssp. bulgaricus and Lactobacillus helveticus. Bioresour. Technol. 99(13), 5951-5955 (2008)

35. Li, H., et al.: An electrokinetic bioreactor: using direct electric current for enhanced lactic acid fermentation and product recovery. Tetrahedron 60(3), 655-661 (2004)

36. Albini, A., Protti, S., Resources, R.: Paradigms in Green Chemistry and Technology, pp. 63-76. Springer, New York (2016) 